\title{
Unnoticed side effect of isoniazid during childhood tuberculosis preventive treatment: Hyperuricemia
}

\author{
Bahar Kandemir ${ }^{1}$, İpek Duman ${ }^{1}$, Yasemin Durduran ${ }^{1}$, Ozge Metin Akcan ${ }^{1}$, Muhammed \\ Burak Selver ${ }^{1}$, and Sevgi Pekcan ${ }^{1}$ \\ ${ }^{1}$ Necmettin Erbakan University Meram Medical Faculty Hospital
}

August 21, 2020

\begin{abstract}
Isoniazid for 6-9 months is the most widely used form of tuberculosis (TB) preventive treatment. We aimed to assess the side effects of isoniazid by using the serum levels of aspartate transaminase (AST), alanine transaminase (ALT), and uric acid (SUA) in children and adolescents receiving long term isoniazid for latent tuberculosis infection. The study included children [?]18 yrs of age who underwent TB preventive treatment with isoniazid (IPT) between 2015 and 2019 at an university hospital. Serum transaminase, SUA, urea, and creatinine levels of patients were measured before the initiation of IPT, 15th day, and once a month during treatment. Patients with either ALT, AST, or SUA results above cut-off levels during treatment were evaluated. The final values in follow up were included in the analysis of the data. A total of 141 children who underwent IPT were included. Seventy children had family members with confirmed tuberculosis disease and 71 children had TST positivity. SUA increased above cut-off values in 16 children (11.3\%) and half of them had uric acid levels over $7 \mathrm{mg} / \mathrm{dL}$. The median duration of the development of hyperuricemia was 4.0 months. ALT or AST increased above cut-off values in 23 children (16.3\%). ALT was above cut-off values in 7 patients, AST was high in 20 patients. The median duration to the development of AST and/or ALT levels above cut-off was 4.0 months. Two patients had hepatotoxic transaminase levels. Three patients had both elevated transaminases and SUA levels. İsoniazid may also cause hyperuricemia beside elevation in transaminases in children.
\end{abstract}

\section{Hosted file}

Tbc bk 17.08.2020 main document.doc available at https://authorea.com/users/352701/articles/ 476845-unnoticed-side-effect-of-isoniazid-during-childhood-tuberculosis-preventivetreatment-hyperuricemia

\section{Hosted file}

Tbc bk 17.08.2020 table 1.doc available at https://authorea.com/users/352701/articles/476845unnoticed-side-effect-of-isoniazid-during-childhood-tuberculosis-preventive-treatmenthyperuricemia

\section{Hosted file}

Tbc bk 17.08.2020 table 2.doc available at https://authorea.com/users/352701/articles/476845unnoticed-side-effect-of-isoniazid-during-childhood-tuberculosis-preventive-treatmenthyperuricemia 